\title{
Analysis of the Growth Perspectives of the Early Stages of Technological Innovation in the Case of the Augmented and Virtual Reality Application
}

\author{
Georgi P. Dimitrov, Galina Panayotova, Rosen P. Toshev, and Iva Kostadinova
}

\begin{abstract}
In this paper, we analyze the introduction and dissemination of the virtual reality (VR) and augmented reality (AR) technologies during the early stages of the innovation-development process. Our primary research method is surveys administered among students in the University of Library Studies and Information Technologies in Sofia, Bulgaria and members of specialized groups and pages on Facebook and LinkedIn. This method provides us with insight about the adoption, use, and application of the emerging virtual and augmented reality technologies.

The Munir and Phillips' model of analyzing the processes that affect social construction and change in institutional fields is utilized in the interpretation of the survey results. Based on the obtained results, we gain valuable insights on how established social practices adapt, new social institutions form, and social roles evolve around the AR and VR technologies in the stage prior to which innovative technologies become widely accepted.
\end{abstract}

Index Terms-Virtual reality, augmented reality, technological diffusion, early stages of technological application.

\section{INTRODUCTION}

The relatively recent consumer introduction and market release of several key hardware pieces such as Google Cardboard (2014), Samsung Gear VR (2015), Oculus Rift (2016), HTC Vive (2016), and Google Tango (2016) has been the subject of a burgeoning amount of academic research. While still at the early stages of the innovationdevelopment process [1], Rauschnabel and Ro, Rese, Baier, Geyer-Schulz, and Schreiber, and Järvinen have observed an increase in the adoption and diffusion of the virtual (VR) and augmented (AR) reality technologies [2]-[4].

According to Statista, by 2018 the number of active virtual reality users is expected to grow to 171 million. The primary interest of these users is gaming [5]. Research by Intel indicates that there are 1.8 billion gamers worldwide [6], which would make the VR and AR adopters, nearly a $10 \%$ segment of the entire video gaming industry. In addition to gaming, Onyesolu argues that "Virtual Reality (VR) is an emerging computer technology that has gained

Manuscript received October 9, 2017; revised December 12, 2017.

Georgi Petrov Dimitrov, Galina Stoianova Panajotova, and Iva Kostadinova are with University of Library Studies and Information Technologies, Sofia, Bulgaria.

Rosen P. Toshev is with London School of Economics and Global Communication from the University of Southern California, UK (e-mail: rob_p01@yahoo.com). wide acceptance in all aspects of human endeavors education, manufacturing/business, exploration, defense, leisure activities and medicine among others" [7]. Furthermore, the rapid advancement of the emerging virtual and augmented reality technologies has been underrepresented in academic literature.

\section{RESEARCh Methodology}

\section{A. Short Description of the Data Collection Process}

By adopting the Munir and Phillips' model of analyzing the processes that affect social construction and change in institutional fields [8], we use a primary method of surveys administered in a paper form to 199 students in the University of Library Studies and Information Technologies, Sofia, Bulgaria and online to 96 members of 40 specialized groups and pages on Facebook and LinkedIn selected due to members' interests in the VR and AR technologies (listed in appendix). The surveys allowed us to detail the existing social practices and the new social institutions that are being shaped by the emerging virtual and augmented reality industries in aspects not solely related to gaming. Based on our findings, we outline the fields of biggest opportunity for growth and challenges in terms of these technology-driven practices and institutions.

The surveys have been conducted during five years among 295 participants $(n=295)$ between 2012 and 2017. Their annual distribution is the following: $2012(n=40)$, $2013(n=40), 2014(n=40), 2015(n=40), 2017(n=135)$. The questions stem from the existing social practices and new social institutions defined by the Munir and Phillips model and are directly related to them. The surveys are conducted in two ways: (1) paper-based questionnaires given to students and (2) online surveys posted on Facebook and LinkedIn to an audience of AR and VR enthusiasts and professionals.

Both versions consist of 25 questions, and each question has a selection of four answer choices with values of 1 to 4 equally distributed among them.

In questions 21 and 22, 1 means "Not at all likely", 2 means "Slightly likely, 3 means "Likely", 4 means "Very likely". The standard deviation $(\sigma)$ of the average of the answers is 1,29 .

\section{B. Methodology}

To complete the data processing and the subsequent analysis of the collected survey data, we have used the following statistical measurements [9]:

- Average value of a given question, calculated by the 
responses of the survey takers

$$
\mu_{q}^{I}=\frac{1}{I} \sum_{i=1}^{I} x_{q, i}^{(i)}
$$

where $q$ is the number of questions, for which $0<=q<=Q$, $Q$ is the number of all questions; $x_{q, i}^{(i)}$ is the answer given by the $i$-th survey taker on the $q$-th question, $I$ is the number of survey respondents in the given group.

- The standard deviation for the q-th question is around the average for the given question.

- The standard deviation for the q-th question is around the average value $\mu_{q}^{I}$ for the given group:

$$
\sigma_{q}^{I}=\sqrt{\frac{1}{I} \sum_{i=1}\left(x_{q, i}^{(i)}-\mu_{q}^{I}\right)^{2}}
$$

Using these measurements, we have conducted analysis based on the responses from all groups. In order to further clarify the problematic questions, we can accept the following definitions:

a) Problematic question is the one, for which $\mu_{q}^{I} \leq \operatorname{avg}\left\{x_{q}^{I}\right\}$. The inequ0ality direction is determined by the manner in which the survey questions are written - i.e. whether the answer with lower value is problematic or not. The problematic questions are marked with '!' in Table I and II.

b) The consolidation around a given question means that $\sigma_{q}^{I}<\sigma^{I}$ when these questions are marked with ' $\S$ ' in Table I and II.

\section{RESULTS AND FINDINGS}

\section{A. AR/VR Capabilities and Purchase Intent}

TABLE I: SUMMARIZED RESULT OF THE RESPONSES TO QUESTIONS 21 AND 22

\begin{tabular}{|c|c|c|c|c|c|c|c|}
\hline \multicolumn{7}{|c|}{$\begin{array}{c}\text { How likely are you to consider } \\
\text { AR/VR capabilities when buying } \\
\text { a new device? (2017) }\end{array}$} \\
& $\begin{array}{c}\text { Very } \\
\text { likely }\end{array}$ & Likely & $\begin{array}{c}\text { Slightly } \\
\text { likely }\end{array}$ & $\begin{array}{c}\text { Not } \\
\text { at all } \\
\text { likely }\end{array}$ & all & $\mu_{q}^{I}$ & $\sigma_{q}^{I}$ \\
\hline Computer & 46 & 40 & 28 & 19 & 133 & 2,85 & $\S 1,05$ \\
\hline Phone & 23 & 44 & 30 & 36 & 133 & $! 2,4$ & $\S 1,06$ \\
\hline
\end{tabular}

There seems to be a positive pattern among the survey participants to consider augmented reality (AR) and virtual reality (VR) capabilities when buying a new computer. In fact, $34.6 \%$ of the respondents marked that they are very likely to consider these capabilities when buying a new computer and $30 \%$ that they are likely to consider them. These are the two most selected categories, respectively. In contrast, AR and VR capabilities seem to be slightly less likely to influence purchase intent for smartphone buyers. $22.6 \%$ of them checked that they are slightly likely to consider these capabilities and $27 \%$ checking that they are not likely at all. However, on this question as well, likely is the most selected response with $33 \%$ of the answers. The results of Table I are visualized in Fig. 1.

\section{Computer:}

$34.6 \%$ - very likely; 30\% - likely; 21\% - slightly likely; $14.3 \%$ - not all likely

\section{Phone:}

$17.3 \%$ very likely; $33 \%$ likely; $22.6 \%$ slightly likely; $27 \%$ not at all likely

\section{How likely are you to consider AR/VR capabilities when buying a new device?(2017)}

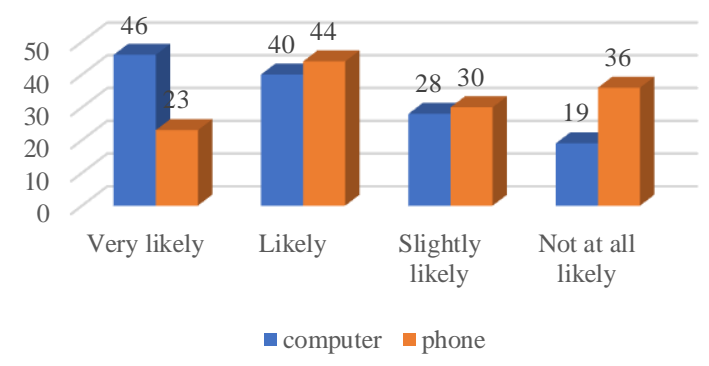

Fig. 1.Visualization of the responses to questions 21 and 22.

\section{B. Shaping New Social Institutions}

TABLE II: NEW SOCIAL INSTITUTIONS BY TYPE AND YEARS

\begin{tabular}{|c|c|c|c|c|c|c|c|}
\hline \multicolumn{1}{|c|}{ New Social Institutions by Type and Year } \\
\hline & $\begin{array}{c}\text { Productivi } \\
\text { ty }\end{array}$ & $\begin{array}{c}\text { Hapti } \\
\text { c VG }\end{array}$ & $\begin{array}{c}\text { 360-degree } \\
\text { imagery \& } \\
\text { video }\end{array}$ & $\begin{array}{c}\text { Comm } \\
\text { unicati } \\
\text { on tool }\end{array}$ & $\begin{array}{c}\text { 3D Prin- } \\
\text { ting }\end{array}$ & $\begin{array}{c}\text { Ans- } \\
\text { wered }\end{array}$ & $\begin{array}{c}\text { All } \\
\text { Resp } \\
\text { onses }\end{array}$ \\
\hline 2012 & 7 & 15 & 2 & 0 & 1 & $\mathbf{2 5}$ & 55 \\
\hline 2013 & 8 & 20 & 1 & 3 & 1 & 33 & 40 \\
\hline 2014 & 17 & 13 & 4 & 0 & 4 & 38 & 40 \\
\hline 2015 & 12 & 7 & 6 & 9 & 2 & 36 & 51 \\
\hline 2017 & 0 & 21 & 38 & 46 & 28 & 133 & 135 \\
\hline
\end{tabular}

TABLE II(A): CONTINUED NEW SOCIAL INSTITUTIONS BY TYPE AND YEAR

\begin{tabular}{|c|c|c|c|}
\hline Years & $\boldsymbol{\mu}_{q}^{I}$ & $\sigma_{q}^{I}$ & $\begin{array}{c}\text { Type of } \\
\text { Question }\end{array}$ \\
\hline 2012 & 0,45 & 0,5 & $!$ \\
\hline 2013 & 0,82 & 0,38 & $\S$ \\
\hline 2014 & 0,95 & 0,22 & $\S$ \\
\hline 2015 & 0,70 & 0,46 & $!$ \\
\hline 2017 & 0,98 & 0,12 & $\S$ \\
\hline
\end{tabular}

The results of our research on new social institutions are exhibited in Table II and Table II (a). The possible answer choices are 5 , each one of them has the value of 1 . The blank responses receive the value of 0 . The average is equal to 0.83 and the standard deviation is 0.41 .

By reviewing the degrees of freedom and the consolidation of the interpreted data, we made the conclusions below. We also derived analogical conclusions, but due to the fact that the number of survey respondents in the given group is too small for statistical representativeness, none of these conclusions are generally summarizing for the given year. In spite of this, the sample is represented here for the purposes of graphic data visualization in 3D space. The results are visualized in Fig. 2 and Fig. 2 (a). 
New Social Institutions

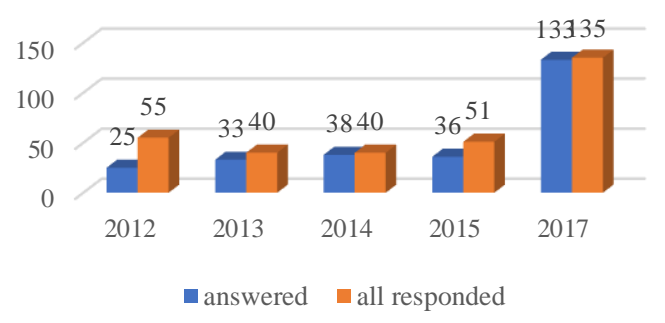

Fig. 2. New social institutions - showing the number of answered surveys for the relevant questions juxtaposed to all survey responses.

\section{New Social Institution by year}

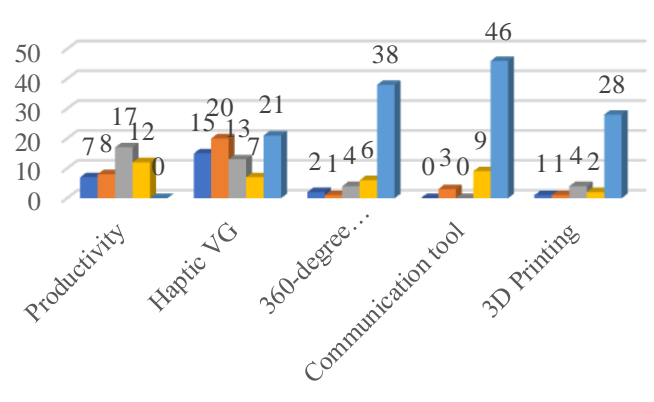

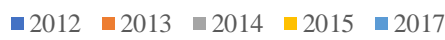

Fig. 2 (a). New social institutions by year.

In the surveys administered during 2017, a tool for communication $(34.5 \%)$ has been marked as the most popular new social institution created by the virtual and augmented reality technologies. This is in line with Rauschnabel, Philipp, Alexander, and Ro's third cluster of motivation for the adoption of smart glasses "maintaining existing social relationships in a similar manner as social networks" [10].

However, in the surveys conducted between 2012 and 2015 haptic video gaming is defined as the most represented new social institution (34.6\%). 360-degree imagery \& video also marks a steep increase, it is the second most selected new social institution (28.6\%) among the questionnaire respondents. In comparison, among the surveys conducted between 2012 and 2015, only 12\% have a tool for communication as their focal point. However, in the surveys taken during 2015, this percentage has increased to $24 \%$. The current apex of $29 \%$ is a continuation of the exhibited trend of bigger emphasis on communication.

\section{Existing Social Practices}

TABLE III: EXISTING SOCIAL PRACTICES BY YEAR AND TYPE

\begin{tabular}{|c|c|c|c|c|c|c|}
\hline \multicolumn{7}{|c|}{ Existing Social Practices by Year and Type } \\
\hline & $\begin{array}{c}\text { Video } \\
\text { Gaming }\end{array}$ & $\begin{array}{c}\text { Exerga } \\
\text { ming }\end{array}$ & $\begin{array}{c}\text { Internet } \\
\text { Browsing }\end{array}$ & $\begin{array}{c}\text { Watching } \\
\text { Online } \\
\text { Video }\end{array}$ & $\begin{array}{c}\text { Answe } \\
\text { red }\end{array}$ & $\begin{array}{c}\text { Total } \\
\text { Respondents }\end{array}$ \\
\hline 2012 & 14 & 1 & 0 & 0 & 15 & 55 \\
\hline 2013 & 4 & 3 & 0 & 0 & 7 & 40 \\
\hline 2014 & 0 & 0 & 1 & 1 & 2 & 40 \\
\hline 2015 & 1 & 2 & 0 & 0 & 3 & 51 \\
\hline 2017 & 50 & 14 & 42 & 27 & 133 & 135 \\
\hline
\end{tabular}

TABLE III(A): CONTINUED EXISTING SOCIAL PRACTICES BY YEAR AND

\begin{tabular}{|c|c|c|c|}
\hline \multicolumn{4}{|c|}{ TYPE } \\
\hline Year & $\mu_{q}^{I}$ & $\sigma_{q}^{I}$ & $\begin{array}{c}\text { Type of } \\
\text { Questions }\end{array}$ \\
\hline 2012 & 0,27 & 0,44 & $!, \S$ \\
\hline 2013 & 0,17 & 0,38 & $!, \S$ \\
\hline 2014 & 0,05 & 0,22 & $!, \S$ \\
\hline 2015 & 0,06 & 0,24 & $!, \S$ \\
\hline 2017 & 0,98 & 0,12 & $\S$ \\
\hline
\end{tabular}

The results of our research on existing social practices are displayed in Table III and Table III (a). There are four possible answers, each one of them is valued at 1 . The blank responses are valued at 0 . The average value is 0.8 and the standard deviation is 0.45 . The analogical conclusions below are made based on the values in Table III.

The established social practice of video gaming is unsurprisingly the most popular established social practice among the questionnaire respondents in 2017 (37.6\% of the total respondents). Video gaming is the most popular existing social practice in the surveys conducted between 2012 and 2015 as well (70\%). In fact, Baciu, Opre, and Riley observe that the improvement of VR hardware "will entice the gaming/software companies to join more heavily into the creation of new games and software" [11].

However, the second most selected practice among the respondents in 2017 is internet browsing (31.6\%), but it is exergaming among the surveys administered between 2012 and $2015(22 \%)$. Table III is visualized in Fig. 3.

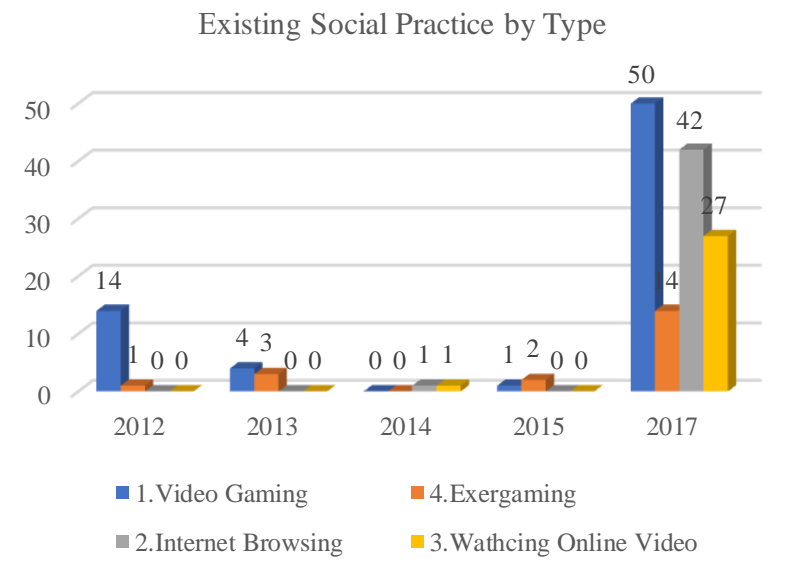

Fig. 3. Existing social practice by type.

\section{Age \& Gender Breakdown Graphic}

TABLE IV: BREAKDOWN BY AGE AND GENDER IN 2017

\begin{tabular}{|c|c|c|c|c|c|c|}
\hline & Total & Male & Female & $\begin{array}{c}\text { Transg } \\
\text { ender } \\
\text { male }\end{array}$ & $\begin{array}{c}\text { Transg } \\
\text { ender } \\
\text { female }\end{array}$ & $\begin{array}{c}\text { Averag } \\
\mathrm{e}\end{array}$ \\
\hline 18 to 24 years & 60 & 40 & 20 & 0 & 0 & 50 \\
\hline 25 to 34 years & 52 & 29 & 23 & 0 & 0 & 26 \\
\hline 35 to 44 years & 12 & 8 & 4 & 0 & 0 & 6 \\
\hline $\begin{array}{c}\text { Age 45 or } \\
\text { older }\end{array}$ & 10 & 8 & 2 & 0 & 0 & 5 \\
\hline
\end{tabular}

Rauschnabel and Ro state that "socio-demographic variables (age and gender) have been found to be associated with technology and media adoption" [2]. The results of the age and gender distribution in 2017 are listed in Table IV. Our findings are based on 134 survey respondents $(\mathrm{n}=134)$, out of which 85 (or $63.4 \%$ ) were male and 49 (or $36.6 \%$ ) 
were female. This creates a ratio of male to female survey participants of 1.73 to 1 . The gender pattern shift from the surveys conducted between 2012 and 2015 is discernable since the ratio of male to female survey takers is 5.5 to 1 .

The survey respondents' demographic breakdown exhibits that the biggest group of participants is men in the 18-24-year-old age bracket (29.8\% of the total respondents), and the second biggest group in terms of gender is also male but in the 25-34-year-old age bracket $(21.6 \%)$. The third biggest group of survey participants is female in the 25-34year-old age bracket (17.2\%). The fourth biggest gender group is also female but in the 18-24-year-old age bracket $(14.9 \%)$. Based on the information from our research methodology, we establish that that the virtual and augmented reality technologies draw biggest interest in the young adult demographic segment. Table IV is visually depicted in Fig. 4.

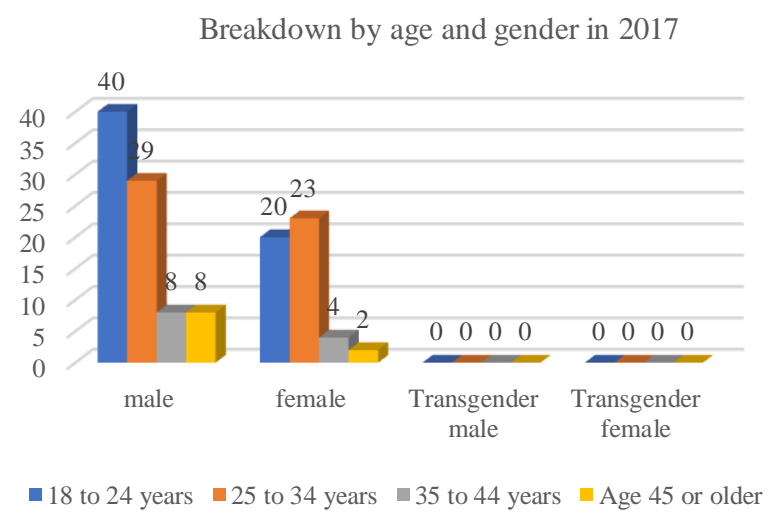

Fig. 4. Visualization of the breakdown by age and gender in 2017.

\section{CONCLUSION}

On the basis of the conducted research, we can conclude that there is a stable shift in the habits of the survey respondents that indicates a burgeoning role of female VR and AR users in the period between 2012 and 2017. In addition to this, the age demographic of $A R$ and $V R$ enthusiasts is predominantly young adults in the 18 to 34 year-old age bracket. The early adopter crowd of adults aged 35 and older is only approximately $16 \%$.

We further summarize that the existing social practice of video gaming is the most popular practice among survey participants in the period between 2012 and 2017. However, the popularity of the social practice of exergaming declines in 2017 and the popularity of the established social practice of internet browsing for AR and VR increases.

Finally, we have observed a steep increase in the application of the 360-degree imagery \& video, communication tool and 3D Printing new social institutions related to virtual and augmented reality technologies, which provides a real perspective for the growth of these technologies in the foreseeable future.

\section{ACKNOWLEDGMENT}

This work was supported by the University of Library Studies and Information Technologies under PPINP-2017-04.

\section{REFERENCES}

[1] E. M. Rogers, Diffusion of Innovations, 5th ed., New York, NY: Free Press, pp. 168-219, 2003.

[2] P. A. Rauschnabel and Y. K. Ro, "Augmented reality smart glasses: An investigation of technology acceptance drivers," International Journal of Technology Marketing, pp. 123-148, vol. 11, 2016.

[3] A. Rese, D. Baier, A. Geyer-Schulz, and S. Schreiber, "How augmented reality apps are accepted by consumers: A comparative analysis using scales and opinions," Technological Forecasting and Social Change, 2016.

[4] A. Järvinen, "Virtual reality as trend contextualising an emerging consumer technology into trend analysis," IEEE Future Technologies Conference (FTC), pp. 1065-1070, 2016.

[5] Statista. (2016). Statistics and facts about Virtual Reality (VR). [Online]. Available: https://www.statista.com/topics/2532/virtualreality-vr/

[6] Technology @Intel. (2015). The Game Changer. [Online]. Available: http://blogs.intel.com/technology/2015/08/the-game-changer

[7] M. O. Onyesolu, "Virtual reality: An emerging computer technology of the 21st century," Electroscope Journal, vol. 1, no.1, pp. 36-40, 2016.

[8] K. A. Munir and N. Phillips, "The birth of the 'Kodak moment': Institutional entrepreneurship and the adoption of new technologies," Organization Studies, vol. 26, no. 11, pp. 1665-1687, 2005.

[9] A. Nikolov and V. Ivanova, "Statistical approach of analysis and visual representation of data on the issues of doctorate education," Scientific Works of University of Rousse, vol. 50, no.6.1, pp. 28-33, 2011.

[10] P. A. Rauschnabel, A. Philipp, B. Alexander, and Y. K. Ro, "Augmented reality smart glasses: Definition, conceptual insights, and managerial importance," The University of Michigan-Dearborn, College of Business, unpublished working paper, 2015.

[11] C. Baciu, D. Opre, and S. Riley, "A new way of thinking in the era of virtual reality and artificial intelligence," Educatia 21, vol. 14, pp. 43-48, 2016.

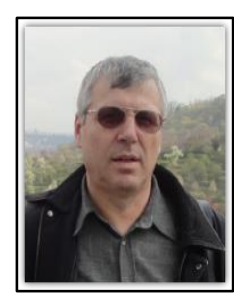

Georgi Petrov Dimitrov is a professor in the University of Library Studies and Information Technologies, Sofia, Bulgaria, a deputy dean of the Faculty of Information Systems and Technologies. His current research interests are big data, web data analytics, and IoT.

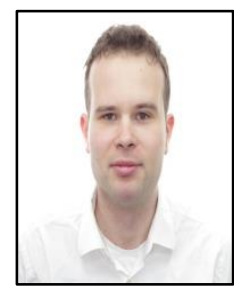

Rosen P. Toshev has graduated with a master of science (MSc) in global media and communications from the London School of Economics and a master of art (MA) in global communication from the University of Southern California. He currently works as a web data analyst in London, United Kingdom.

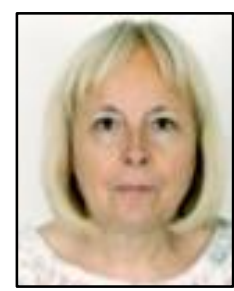

Galina Stoianova Panajotova is a professor in the University of Library Studies and Information Technologies. Her current research interests are mathematics and statistics.

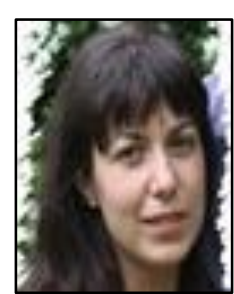

Iva Kostadinova is an assistant professor in the University of Library Studies and Information Technologies. Her current research interests are issues of higher education and software programing. 